\title{
Flexible Working and Unpaid Overtime in the UK: The Role of Gender, Parental and Occupational Status
}

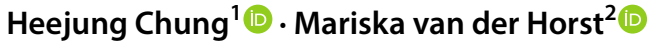

Accepted: 7 November 2018 / Published online: 26 November 2018

(c) The Author(s) 2018

\begin{abstract}
Recent studies have shown that flexible boundaries between work and family may make employees work harder and longer. Yet most studies were not able to show whether there are differences across different types of flexible working arrangements, and whether this relationship may only hold for certain groups of workers. We examine how three different types of flexible working arrangements, that is schedule control, flexitime, and teleworking, are associated with an increase in unpaid overtime hours of workers in the UK using the Understanding Society data from 2010 to 2015 and fixed effects panel regression models. Results show that the flexible arrangements that were introduced primarily for work-life balance purposes, i.e., flexitime and teleworking, do not necessarily increase unpaid overtime hours significantly. On the other hand, workers' control over their schedule, mainly introduced as a part of high-performance strategies, leads to increased unpaid overtime hours. This is especially true for professional men, and women without children, especially those working full-time, and surprisingly part-time working mothers. The results of this study point to the importance of distinguishing between different groups of workers as well as between different types of arrangements when examining outcomes of flexible working. Furthermore, the results of the study contribute to the argument that performance enhancing flexible working arrangements can potentially exacerbate gender inequalities in the labour market by enabling men to commit more time to their jobs, while for women, especially full-time working mothers, this may be less possible.
\end{abstract}

Keywords Flexible working · Schedule control · Flexitime · Teleworking · Working hours · Overtime $\cdot$ Gender $\cdot$ UK $\cdot$ Fixed effects panel regression

Electronic supplementary material The online version of this article (https://doi.org/10.1007/s1120 5-018-2028-7) contains supplementary material, which is available to authorized users.

Heejung Chung

h.chung@kent.ac.uk

Mariska van der Horst

m.f.j.vanderhorst@vu.nl

1 School of Social Policy, Sociology and Social Research, Faculty of Social Science, University of Kent, Room 106, Cornwallis Northeast, Canterbury CT2 7NF, UK

2 Department of Sociology, Vrije Universiteit Amsterdam, Amsterdam, The Netherlands 


\section{Introduction}

Increasing numbers of companies and governments are introducing flexible working, that is giving workers control over when and where they work, as a less costly option to help working families manage work and family demands compared to, for example, paid leaves (Eurofound 2015; Chung 2017b). According to the work-family border theory (Clark 2000), and based on the work resources theory (Voydanoff 2004) providing workers with the flexibility and control over the temporal and physical boundaries between their work and home domains should help workers' work-family integration and thereby reduce workfamily conflict (Steiber 2009; Van der Lippe and Lippényi 2018). However, according to a systematic review of the relationship between flexible working and work-family conflict, the influence was rather small in magnitude if found at all (Allen et al. 2013; see also, Golden et al. 2018; Chung and Van der Lippe 2018). Further, other studies have shown that certain types of flexible working, such as teleworking, are likely to increase workfamily conflict rather than reduce it (e.g., Golden et al. 2006). One reason behind this is the work-family boundary blurring and multi-tasking that can occur through flexible working (Schieman et al. 2009), which can increase work-family conflict. The potential expansion of both work and care capacity through flexible working can also explain this partially-e.g., parents are able to spend more time with their children when working flexibly (Craig and Powell 2012; Noonan et al. 2007) or are able to maintain their work intensity through flexible working in times of increased care demands (Chung and Van der Horst 2018; Fuller and Hirsh 2018). Another reason why flexible working may not necessarily lead to a better work-life balance, is because there is a tendency for workers to work harder and longer when working flexibly. This phenomenon has been coined 'the autonomy (control) paradox' (Mazmanian et al. 2013; Putnam et al. 2014), the paradox being that workers when given more autonomy and freedom, rather than working less, work harder and longer. In fact, recent studies have shown that flexible working increases working hours, overtime (Glass and Noonan 2016; Lott and Chung 2016), and work intensity (Kelliher and Anderson 2010). Although these studies have been useful in providing some insights, there are some issues that need further investigation.

Most importantly, most have been qualitative case studies specific to certain occupations and/or companies (see for a review, Mazmanian et al. 2013; Kelliher and Anderson 2010). In addition to issues around generalisation, there is little scrutiny of how the relationship may vary between different groups of workers. Flexible working can be used by workers for a variety of reasons. Previous research demonstrates that it is used, and expected to be used, for different purposes depending on the workers' gender, parental status, and occupation (Singley and Hynes 2005; Brescoll et al. 2013; Munsch 2016; Gerstel and Clawson 2014). Thus, we can expect that outcomes, including increased unpaid overtime, will depend on the purpose for which flexible working is used for. Of particular interest for us are the gender discrepancies. Previous studies have noted that flexibility in their work could potentially allow workers to "do gender" (Clawson and Gerstel 2014) with women using flexibility to meet their family demands while men use it for performance enhancing goals (Lott and Chung 2016; Kim 2018; Kurowska 2018). In other words, flexible working can increase rather than decrease the working hours gap between men and women, which has been shown to be one of the most important factor explaining the gender wage gap (Goldin 2014; Cha and Weeden 2014). Given that working hours, and specifically unpaid overtime hours are considered one of the most important determinants of future promotion chances and pay (Francesconi 2001; Pannenberg 2005), and for keeping ones' job during 
recession (Warren 2015), such gendered discrepancies in flexible working outcomes can increase rather decrease the gender wage gap.

Another limitation to the existing studies is that they mostly examined one specific type of flexible working arrangements and/or were not able to distinguish between the different types of flexible working arrangements - namely, those mainly introduced to allow workers to address family demands, from those mainly introduced for performance enhancing purposes (see also, Ortega 2009; Osterman 1995). Studies of employers have found that flexible working is used for a wide range of reasons, including for cost-cutting performance enhancing goals and to meet workers' work life balance demands (Riedmann et al. 2006). Not differentiating between these different types of flexible working may lead to unintentional critique towards flexible working practices that do allow for a better work-life integration. In this study, we examine three distinct flexible working arrangements based on the unique dataset we are able to use, namely, Understanding Society (2009-2015), a large household panel survey in the UK. Firstly, we examine flexitime and teleworking, introduced by law in the UK primarily to enhance the work-life balance of workers, and compare their effect against schedule control, primarily used to give workers more control over their work to enhance performance outcomes (Wood and De Menezes 2010) and/or given to those with more seniority (Schieman et al. 2009). Fixed effects panel regression models are used to examine how these three types of flexible working are associated with an increase in unpaid overtime hours. Although previous studies have examined overtime as a whole (Lott and Chung 2016; Glass and Noonan 2016), paid overtime may be done for additional income and/or can be carried out more routinely as a part of the job. We believe that unpaid overtime is a better measurement of workers working longer to enhance performance, or adhere to the ideal worker norm, which can be more problematic in relation to work-life balance and gender equality. We also model different groups of workers separately to see whether this increase is found only for a specific subgroup of workers. Section 2 will examine some definitions of key concepts, theoretical frame our research questions, and present our hypotheses. The following section, Sect. 3, will discuss data and methods. Section 4 provides results and the paper ends with a conclusion and discussion.

\section{Background}

\subsection{Flexible Working Definitions}

Flexible working can entail employee's control over when they work or where they work (Kelly et al. 2011; Allen et al. 2013). More specifically, flexitime/schedule control entails worker's ability to change the timing of their work (that is, to alternate the starting and ending times), and/or to fluctuate the numbers of hours worked per day or week-which may also include accumulating hours for days off. In the broader sense, flexitime can also include annualised hours, where working hours are not defined per day or week but calculated throughout the year, and compressed hours, where workers maintain their working hours, usually full-time, but work fewer days-e.g., four rather than five days. Teleworking allows workers to work outside of their normal work premises, e.g., working from home. Although flexible working can also include workers having control over how much they work-e.g., part-time work, term-time only and job sharing, for the purposes of this paper 
when we refer to flexible working, this entails flexitime (in the broader sense, and including schedule control) and teleworking only.

Flexible working can be employer- or employee-friendly depending on whose demand it aims to (primarily) serve (Chung and Tijdens 2013; Riedmann et al. 2006). Flexible working is usually considered a family-friendly arrangement that can provide workers with the capacity to form and blend the boundaries of their work to allow a better fit to their family demands (Clark 2000). In fact, several empirical studies show that workers, especially women, frequently use flexibility in their work to address various family demands (Maume 2006; Craig and Powell 2012; Singley and Hynes 2005).

Control over one's work, however, can also be used for performance enhancing purposes as a part of companies' high-involvement/performance work systems (Wood and De Menezes 2010). In the high performance work systems approach, it is believed that giving workers more discretion and influence over their work, including control over when and where they work, can help increase performance (Appelbaum 2000; Davis and Kalleberg 2006). In fact, in 2004 surveying companies across 21 European countries, when asked why they have introduced arrangements that give workers more control over schedules in their companies, more than half of all employers note that it was for performance/profit enhancing related purposes (Riedmann et al. 2006).

Enhancing worker's work life balance and increasing performance outcomes can go hand in hand (Rapoport et al. 2002), where family-friendly flexible working may ultimately result in enhanced performance outcomes - as also argued in the literature on the business case of flexible working (de Menezes and Kelliher 2011; Yasbek 2004; Dex and Scheibl 2001). Similarly, performance oriented flexible working may be used by workers to better adapt to family life as well (Young 2018). However, as we will show later, employers may have different reasons as to why they provide workers more control over their work, and therefore there may be different reasons as to why workers take these arrangements up (see also, Leslie et al. 2012). This would then also affect the outcomes of flexible work arrangements (Chung 2018a; Ortega 2009; Clawson and Gerstel 2014). Previous studies that examine how flexible working relates to increases in work intensity/overtime hours do not necessarily tease these differences out. For example, Lott and Chung (2016) primarily focussed on workers' control over their schedules while Glass and Noonan (2016) looked at working from home, which included taking work home after normal working hours. As we will show later, distinguishing the different types of flexible working based on which goal it is primarily aimed at, is crucial when examining the outcomes of flexible working.

The UK provides a unique opportunity to assess different types of flexible working arrangements because flexible working for family-friendly purposes is installed in the labour law. The UK's right to request flexible working was introduced in 2003 "under the banner of enhancing parenting choice" (Lewis et al. 2008: 272) in the context of lack of other means for parents to address work-life balance issues. This right was first provided to parents of children under the age of six and children with a disability up to the age of 18. In 2007, this was extended to carers of adults, and parents with children below the age of 17 , and finally extended to cover all workers from the summer of 2014 . The burden of the request lies on the worker, and employers can reject this request on various business grounds (ACAS 2016). Understanding Society data captures workers' access to and use of the arrangements specified in this legislation, including flexitime and teleworking, which we understand as arrangements aimed primarily to enhance the work-life balance of workers. This can be distinguished from schedule control, which measures workers' control over their work schedules and is asked in a series of question measuring the extent to which high-involvement work systems are used in the workplace. It is measured alongside 
information on workers' control over how they carry out their work in general-e.g., which tasks and order of work. We argue that these arrangements measure flexible working primarily aimed to enhance performance outcomes. Again, despite the possibility of these arrangements indirectly enabling the achievement of the other goals, we expect that the primary goals of these arrangements may shape the way they influence the outcomes.

\subsection{Flexible Working and Unpaid Overtime}

Examining knowledge professionals in the US and their use of mobile devices for work purposes, Mazmanian et al. talk about 'the autonomy paradox'; when enhancing individual's control over when and where they can work, leads to a "collective spiral of escalating engagement, where they end up working everywhere/all the time" (2013: 1338). In other words, the study provides an account of how flexibility and control over one's work results in the expansion of work and the work domain. Several theories can explain the causes of such intensification (see, Kelliher and Anderson 2010; Lott 2018). Firstly, it can be explained through the gift exchange theory. This theory suggests that to reciprocate for the favourable work arrangements provided to them as a "gift" by the employers, workers expend greater effort, increase work motivation and commitment which leads them to work harder or longer.

Another way flexible working can increase work intensity is through enabled intensification. For example, flexible working has been shown to decrease performance reducing issues such as sickness and absenteeism (see also, de Menezes and Kelliher 2011). Furthermore, enabled intensification can also occur by allowing workers to work their most productive hours and thereby removing potential distractions when working, or by reducing commuting times when working from home (Kelliher and Anderson 2010). However, enabled intensification can also happen as a result of increased competition between workers in workplaces where boundaries between work and other spheres of life are relaxed and there exists a culture of working all the time and everywhere (Williams et al. 2013; Eurofound and the International Labour Office 2017). This can especially be the case when flexible working arrangements are not necessarily introduced for family-friendly purposes but to enhance workers' performance. When used to meet performance enhancing goals, flexible working is usually used alongside other performance enhancing arrangements such as self-managed team work, job rotation, and performance related pay (Ortega 2009; Chung 2014). When flexible working is accompanied by indirect measures to increase performance and output (Felstead and Jewson 2000), workers may (need to) work extra hours when given more control over their work to meet the targets set for them.

Next to enabled intensification, workers may also have to work harder and longer due to enforced intensification (Kelliher and Anderson 2010). This can be done where a move away from fixed hours can enable employers to expand work through the back door, without issues with overtime premiums, or restrictions on maximum number of hours worked, and other restrictions currently set by labour laws. On the other hand, employers may explicitly give workers more control and autonomy over their work only in exchange for increased work intensity or overtime hours, somewhat like the gift exchange but here orchestrated by employers (Bathini and Kandathil 2017).

Flexible working introduced for family-friendly purposes may increase performance outcomes through the increase in work intensity of workers especially through the gift exchange and reduction of sickness/absenteeism it can bring. However, it is less likely that family-friendly flexible working will lead to an increase in unpaid overtime, and even 
if it does this is likely to be minimal. This is especially the case when we consider that, at least in this dataset, the workers taking up the more family-friendly flexible working arrangements would have had to actively request the use of these arrangements most likely because of the demands coming from their family spheres they need to meet and/or due to their preference for a better work-life balance. Rather, we believe that it is the performance enhancing flexible working arrangements that will lead to (a larger) increase in unpaid overtime hours. To be able to assess our claims, we will analyse both family-friendly and performance oriented arrangements, but expect to find significant increases in unpaid overtime for performance oriented flexible work arrangements only.

Hypothesis 1 We expect the performance oriented flexible working arrangement to be associated with increased unpaid overtime hours, while family-friendly flexible working arrangements may not be.

\subsection{Differences Between Groups of Workers in Unpaid Overtime}

Various studies suggest that flexible working may entail and is expected to entail different things for different groups of workers (Gerstel and Clawson 2014; Brescoll et al. 2013). Clark (2000) argues that the outcomes of flexibility between the borders of the work and home domain will depend on the strength of the border, the domain the individual identifies with most, and the priority each domain takes in one's life. In other words, the flexibility of the border between the work and home domains is most likely to lead to an increase in unpaid overtime for workers who (need to) identify closely to the work domain and for whom the work domain takes priority. Sometimes this is not voluntary due to the breadwinning role the worker may have. On the other hand, those workers who prioritize the home domain and (are pressured to or need to) identify with the home domain may be restricted in their ability to work extra hours. In this paper, we argue that the strength of the work and home domain will differ across workers of different sex, parental status, and occupational levels.

For many women, family remains an important domain to identify with because women still do, and are expected to do, the majority of household tasks and care work (Bianchi et al. 2012; Park et al. 2013). For this reason, women are more likely than men to use flexible working to facilitate family demands (Singley and Hynes 2005; Gerstel and Clawson 2014; see also, Kim 2018; Kurowska 2018), especially when family demands are not flexible (e.g., school opening times) and/or when family demands are unpredictable (e.g., a child becoming ill). On the other hand, men are more likely to, and expected to, prioritize and identify with their work domain. They are also better able to do this because of the support they receive from their partners in regards to care and domestic work (Moen and Yu 2000; Williams et al. 2013). Thus, men are more likely to (be able to) use flexible working for career and performance enhancing purposes (Gerstel and Clawson 2014) and to expand their work domains with flexible working (Lott 2018). By allowing men and women to "do gender" (West and Zimmerman 1987), flexible working can potentially traditionalise gender roles (Lott and Chung 2016)_increasing the unpaid overtime hours of men but not for women.

Hypothesis 2a Performance oriented flexible working is associated with an increase in unpaid overtime hours for men but not for women 
However, rather than gender, or gender alone, the care responsibility the worker has, especially in relation to childcare, may be of greater importance. There is a general expectation in the UK that mothers take main responsibility of childcare, and thus should either stay home or work part-time especially when children are under school age (Park et al. 2013). This explains the patterns found in the gender gap in employment rates in the UK for 2015. Although there are no differences in employment rates between men and women aged 25-49 without children (both at 85\%), when comparing men and women with children the gap increases, with the employment rates of fathers and mothers at $92 \%$ versus $71 \%$ respectively (Eurostat 2016a). Women are also more likely to work part-time post childbirth due to childcare responsibilities, with more than half of all working mothers in part-time jobs in the UK in 2015, while only $16 \%$ of women without children and $6 \%$ of men, both with and without children, do so (Eurostat 2016b).

Mothers working part-time may already be signalling the demands they face in their family roles (Tomlinson 2007), and their unwillingness or inability to adhere to the "ideal worker norm"- a worker who prioritizes work above other aspects of their lives (Williams 1999). Mothers working part-time may be unwilling or unable to increase their (unpaid) overtime hours due to the existing family demands that (they feel) cannot be sacrificed (Durbin and Tomlinson 2010). When working full-time, however, women and mothers might be signalling their prioritization of work, i.e., putting greater value towards their work. They may also be those who need to work more for financial reasons. Even if this were not the case, they may be in a position where they can or have to comply with the expectations of an ideal worker set by their employer and colleagues, and may use flexible working in a similar manner as men/fathers.

Hypothesis $\mathbf{2 b}$ Performance oriented flexible working is associated with an increase in unpaid overtime hours for women without children, but not for mothers, while the association is found for both fathers and non-fathers

Hypothesis 2c Performance oriented flexible working is associated with an increase in unpaid overtime hours for full-time working parents, both mothers and fathers, but not for part-time working mothers

Finally, we argue that occupational levels are important in differentiating between the potential outcomes of flexible working. Many studies have shown that higher occupational groups are more likely to have access to flexible working arrangements compared to lower occupational groups (Swanberg et al. 2005; Golden et al. 2018; Chung 2018a). This may especially be the case for the more performance oriented arrangements (Chung 2017a). Higher occupational groups/professionals are more likely to (have to) adhere to the work devotion schema compared to lower occupational groups-i.e., "the moral and institutionalised cultural mandate that work demands and deserves total allegiance" (Cech and Blair-Loy 2014: 87). Using flexibility to meet family demands will violate the cultural beliefs of a higher status worker (Schieman et al. 2009). Thus, higher occupational groups may be much more likely to use the increased control over their work to extend their devotion to work than lower occupational groups. However, again it may be the men/fathers in professional and managerial roles who are able to adhere to the ideal worker culture through flexible working. In addition to the support they are more likely to receive at home from their spouses, they are also likely to have higher incomes 
which reduces the need for their spouses to take on additional bread-winning roles. Due to the competing demands professional mothers face coming from both work and family domains, their capacity to expand their unpaid overtime hours may be limited (BlairLoy 2009). On the other hand, professional/managerial women without children may be able to adhere more to the cultural norms and expand their unpaid overtime hours as much as men.

Hypothesis 2d Performance oriented flexible working is associated with an increase in unpaid overtime for higher occupational groups but not for lower occupational groups

Hypothesis 2e Performance oriented flexible working is associated with an increase in unpaid overtime for fathers, and childless men and women in higher occupational groups, but not for mothers in higher occupational groups

\section{Data and Method}

\subsection{Data}

We used Understanding Society (University of Essex, 2016) waves 2, 4, and 6 (2010/2011, $2012 / 2013,2014 / 2015$ ) to look at our research question. Understanding Society is a large household panel data with data of, in wave 1, about 40,000 households in the UK (Knies, 2015). In waves 2,4 , and 6 , respondents were asked about their flexible work arrangements. We excluded proxy interviews, but did not balance the data (in a robustness check we balanced the data to see to what degree that mattered for our conclusions, see online supplementary material Web Appendix 3) and selected those respondents for whom it was possible to combine the household data with the individual data (over $97.9 \%$ of the cases in each wave). We also exclude those not in paid employment (including currently on maternity leave) or who were self-employed as they have more autonomy over their work by default. We further excluded respondents who were close to or at their state pension age in any of the waves (we excluded women aged 60 or older and men aged 65 or older based on the traditional State Pension Ages in the UK) as well as individuals who are still of a compulsory education age $(<18)$. Ten respondents seemed to change sex over the waves and are deleted as most of our hypotheses are sex specific and there are not enough respondents changing sex to make this a separate category. We ended up with 30,761 respondents, of which 14,846 were men and 15,915 were women. The total number of respondents in the analyses are lower due to missing data. The consequences of missing data are assessed in a robustness check (see online supplementary material Web Appendix 3).

\subsection{Variables}

\subsubsection{Dependent Variable}

The main dependent variable in this study is the number of unpaid overtime hours worked by the respondent. In the survey, respondents were asked the number of hours they worked overtime in a normal week. This variable ranged from zero to $90 \mathrm{~h} / \mathrm{week}$. Next to this question, respondents are also asked how much of that is usually paid overtime. To derive 
unpaid overtime, we subtract the number of paid overtime hours from the total overtime hours. We set the maximum to $30 \mathrm{~h} /$ week since less than half a percent worked more than $30 \mathrm{~h} /$ week overtime. The consequence of top-coding this variable is assessed in a robustness check (see online supplementary material Web Appendix 3).

\subsubsection{Flexible Working Variables}

Our main explanatory variables are the access to and use of flexible working arrangements. Here we distinguish between three types of working time arrangements, namely flexitime, telework, and schedule control. For the first two working time arrangements, we use the part of the survey questionnaire where respondents were asked about their access to and use of various types of flexible working arrangements included in the right to request flexible working in the UK legislation, which was introduced to increase the work-life balance of parents (see 'Background' on 'Flexible working definitions' above). Respondents were asked; "I would like to ask about working arrangements at the place where you work. If you personally needed any, which of the arrangements listed on the card are available at your workplace" (emphasis by authors). The list mirrors the legislation and government websites explaining the right to include; part-time working, working term-time only, job sharing, flexi-time, working a compressed week, working annualised hours, working from home on a regular basis, "other flexible working arrangements", or none of these. Given this context, we believe that these questions measure the more family-friendly flexible working arrangements. Those who have answered that they have the arrangements available were also asked whether they were currently using them. Based on these questions we made four variables. To measure (1) access to and (2) use of flexitime, we combined flexi-time, compressed hours, and annualised hours. Similarly, to measure (3) access to and (4) use of telework we used working from home on a regular basis. Later on in our robustness checks, we examine flexitime when compressed hours and annualised hours are not included in the definition (results in online supplementary material Web Appendix 3). Any individual who did not have access to a flexible work arrangement was also not able to use it, and thus coded as not using this arrangement.

In another part of the survey, respondents are asked about the control they have over their work; including the tasks, the pace, the method and order in which they do their job. Amongst these, workers were also asked "In general, how much influence do you have over... the time you start or finish your working day?" We consider this question as measuring 'schedule control', i.e., flexible working that relates more to high-performance strategy flexible working arrangements. Answering categories were (1) A lot, (2) Some, (3) A Little, and (4) None. We reverse coded this variable that a higher score meant more schedule control and use it as a categorical variable. As we show in detail in online supplementary material Web Appendix 1, although flexitime and schedule control may essentially mean the same thing, the people who (say they) have access to/use flexitime are not necessarily the same persons who (say they) have a lot of schedule control, suggesting that these arrangements are used by/provided to different groups of employees, probably to serve different purposes. We note however, that we do not know why these arrangements were provided by the employer and taken up by workers, and cannot guarantee that the assumptions made here are completely in line with the motivations of workers and employers. However, we expect most problems to exist with schedule control. Given the UK policy context and the preface "if you personally needed any", we expect that most respondents will have thought about work-life balance strategies with flexitime and telework. Schedule control 
does not have a prefix signalling to focus on high-performance strategy flexible working arrangements, making it possible that this question was interpreted more broadly. However, if the theoretical discussion is correct, and it is mainly these high-performance strategies that will affect unpaid overtime, then this will lead to an underestimation of the true effect, making this a conservative test of our hypotheses. ${ }^{1}$

\subsubsection{Key Groupings}

The key groups we distinguish in this paper are men and women; parents as defined by those who live with a child under the age of 12 in the household vs non-parents (including those who may be parents but are not currently living with their children); those working part-time vs full-time (defined as those working $35 \mathrm{~h}$ a week or more ${ }^{2}$ ); and higher occupational group (defined as those in the first three classes of the ISCO 1 digit occupations-i.e., Managers, Professionals, and Associate Professionals and Technicians) vs those in other occupational groups (all other ISCO groups). This grouping also represents the groups that are more likely to have access to flexible working arrangements (Chung 2017a, 2018a; Wiß 2017).

\subsubsection{Control Variables}

Based on previous literature, we included a number of control variables. They are: total number of children (4 categories); age of the youngest child (5 categories); age of the respondent (continuous); whether the respondent has a degree (yes/no); whether the respondent works in private sector (yes/no); whether there is a union present in the respondent's workplace (yes/no); whether the respondent has managerial duties (3 categories); working hours of the respondent (continuous and only in models where full-time and part-time workers are not distinguished); whether there is performance related pay in the respondent's workplace; whether the respondent changed job; whether the respondent is the breadwinner in the household (defined as contributing at least $60 \%$ of combined individual and respondent's partner's earnings); whether the respondent is on a fixed term or a permanent contract; whether the respondent lives with a partner; whether this partner is employed or self-employed (compared to not employed); working hours including overtime of the partner (continuous); earnings of the partner $(\log )$; whether the partner uses flexible working arrangements (combination of flexitime and telework); and whether the partner has schedule control (4 categories). Details on these control variables can be found in the online supplementary material Web Appendix 1.

\subsection{Models}

To test our hypotheses we performed fixed effects panel regression models to assess how many unpaid overtime hours the respondent works, treating the dependent variable as

\footnotetext{
${ }^{1}$ It is also possible that teleworking/working from home is also done as a part of high performance systems, but in this questionnaire there is no scope to distinguish between the different types of teleworking as is done for schedule control.

2 This distinction between full-time and part-time on $35 \mathrm{~h} /$ week is based on the UK Government (https:// www.gov.uk/part-time-worker-rights). See Lyonette (2015) for more information about part-time work in the UK and Warren (2015) on how part-time work has changed (and not changed) since the last recession of 2008-2009.
} 
Table 1 Flexible working and unpaid overtime hours-full sample (fixed effects model with robust standard errors). Source: Understanding Society

\begin{tabular}{|c|c|c|c|c|}
\hline \multirow{3}{*}{$\begin{array}{l}\text { Model } \\
\text { Variable }\end{array}$} & \multicolumn{2}{|l|}{ Men } & \multicolumn{2}{|l|}{ Women } \\
\hline & \multicolumn{2}{|l|}{$1-1$} & \multicolumn{2}{|l|}{$1-2$} \\
\hline & Coefficient & $p$ value & Coefficient & $p$ Value \\
\hline Flexitime available but not use & -0.12 & 0.286 & $-0.39 * * *$ & $<.001$ \\
\hline Use flexitime & 0.12 & 0.419 & 0.01 & 0.906 \\
\hline Telework available but not use & 0.24 & 0.166 & 0.17 & 0.248 \\
\hline Use telework & 0.30 & 0.252 & 0.11 & 0.688 \\
\hline \multicolumn{5}{|l|}{ Schedule control } \\
\hline \multicolumn{5}{|l|}{ None (ref) } \\
\hline A little & 0.18 & 0.101 & 0.12 & 0.236 \\
\hline Some & $0.42 * * *$ & 0.001 & $0.40 * * *$ & 0.001 \\
\hline A lot & $0.63 * * *$ & $<.001$ & $0.40 * *$ & 0.003 \\
\hline Number of observations & 18,840 & & 19,132 & \\
\hline Number of respondents & 10,201 & & 10,609 & \\
\hline $\mathrm{R}^{2}$ within & 0.03 & & 0.03 & \\
\hline $\mathrm{R}^{2}$ between & 0.09 & & 0.04 & \\
\hline $\mathrm{R}^{2}$ overall & 0.10 & & 0.05 & \\
\hline
\end{tabular}

This model controls for a wide range of individual, household and company level characteristics. Full models can be found in online supplementary material Web Appendix 2

Bold indicates $p \leq 0.050$

$* *$ indicates $p \leq 0.010$

$* * *$ indicates $p \leq 0.001$

continuous and using robust standard errors. Employees may self-select into jobs where flexibility is available, and employees with certain time-invariant characteristics may be those who are also likely to seek jobs that allow them to have control over where or when they work and/or are more willing to work overtime. Fixed effects models control for such time-invariant effects, even if they are not measured, by only taking variation within an individual into account. All our analyses are separated out by sex as we hypothesise different effects for men and women (see 'Background') and also expect certain control variables to work differently for men and women. We present main findings in our tables and full models including all control variables can be found in the online supplementary material Web Appendix 2.

\section{Analysis Results}

In this section, we will examine the results for the family-friendly flexible working arrangements first, and then move on to the high-performance work systems schedule control arrangements. When we examine family friendly flexible working arrangements' association with unpaid overtime hours, for the most part, we found insignificant results. The use of flexitime or teleworking was not significantly associated with an increase in unpaid overtime hours for the general population nor for the other sub-groups (as shown in Tables 1, 2, 3, 4, and 5 and Figs. 1, 2, 3, 4, and 5). For the majority of the 


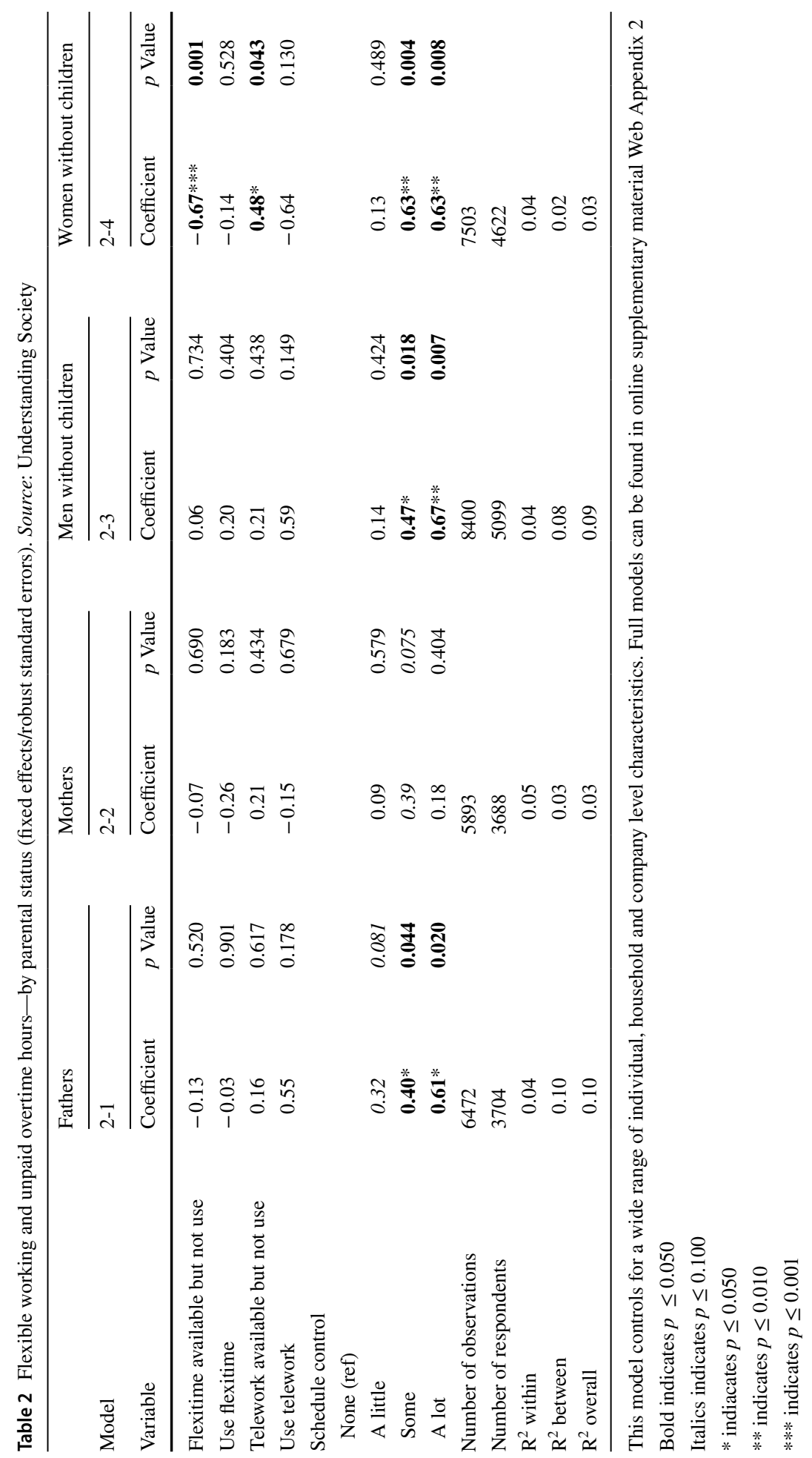




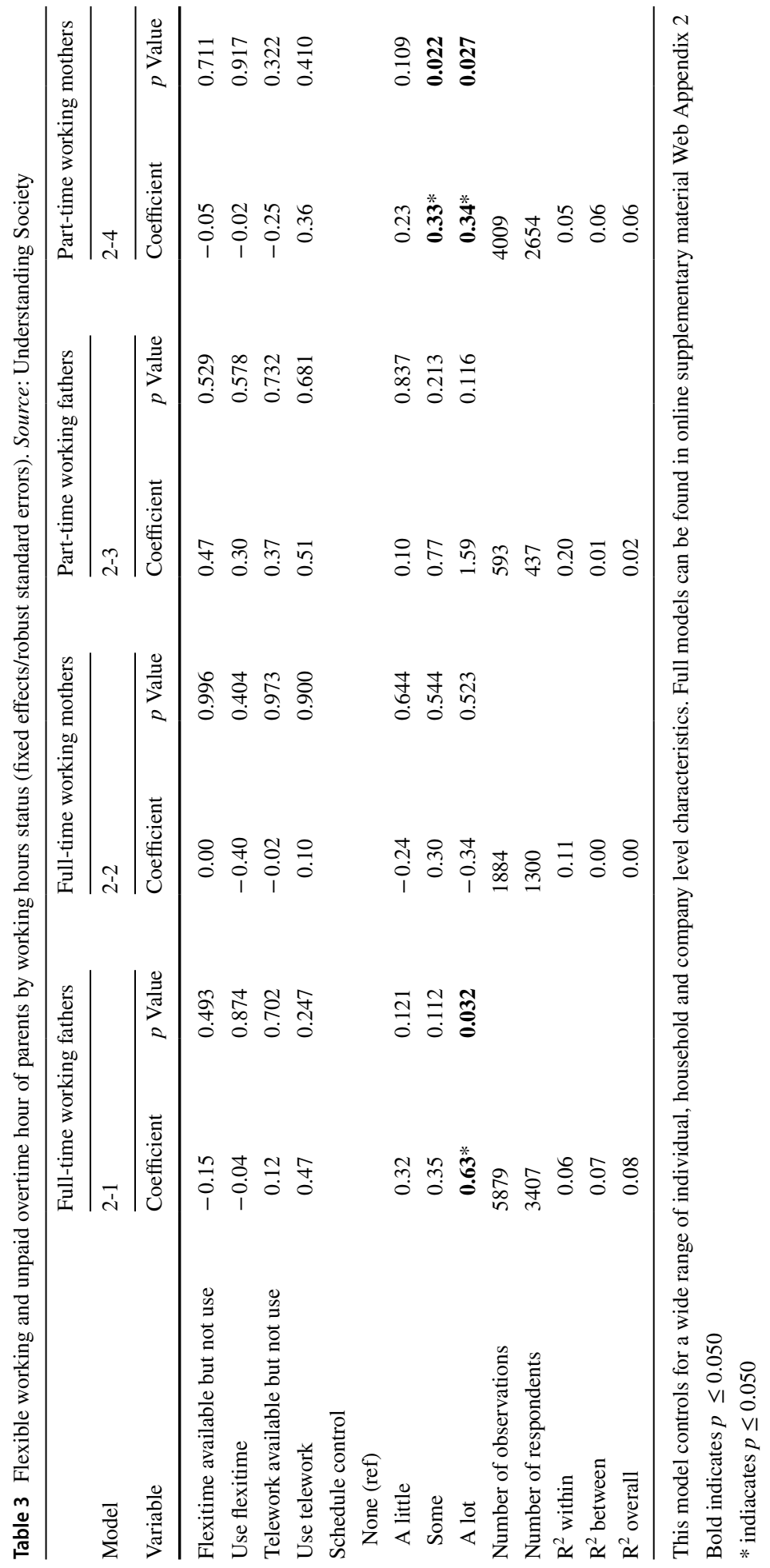




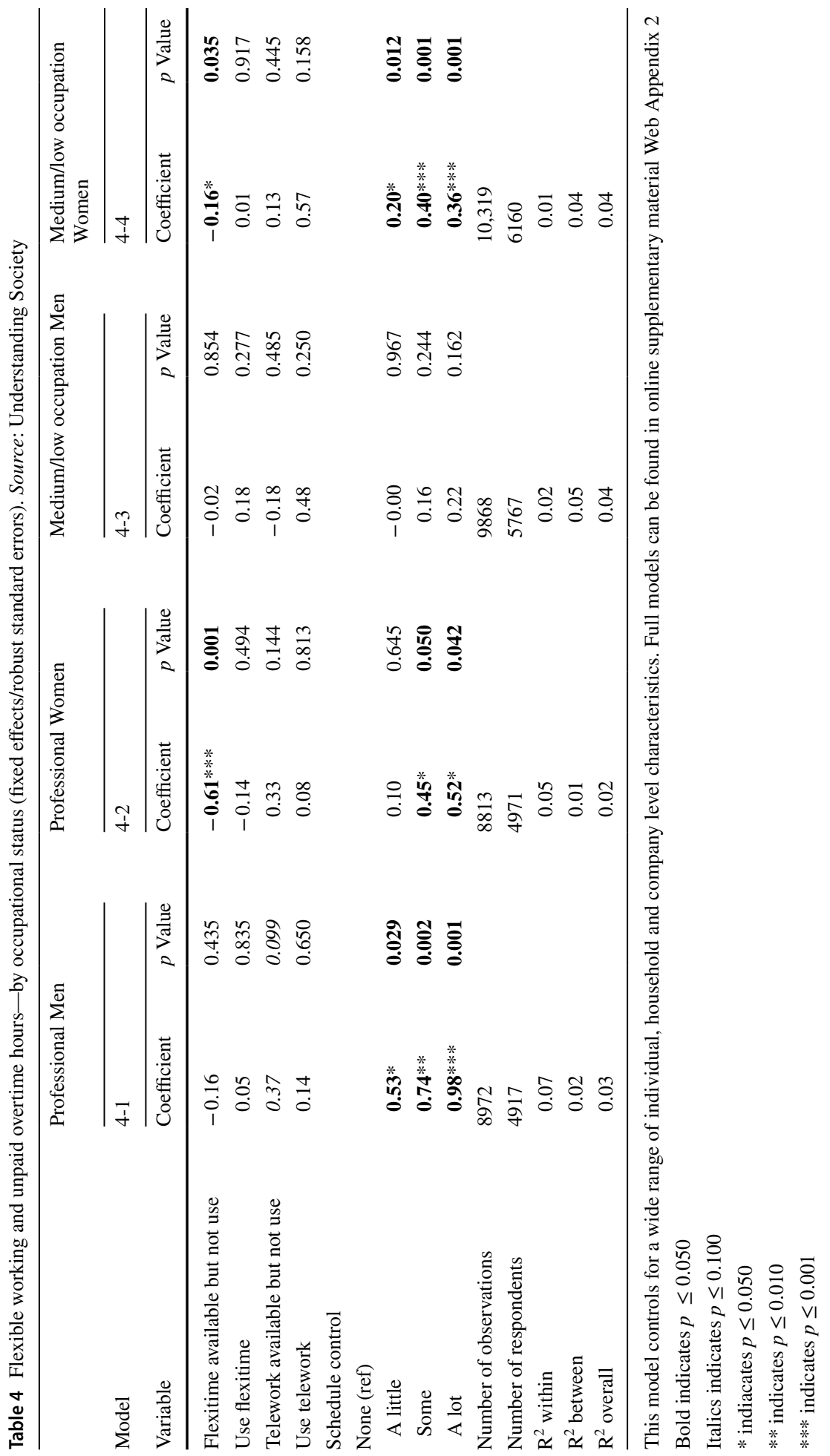




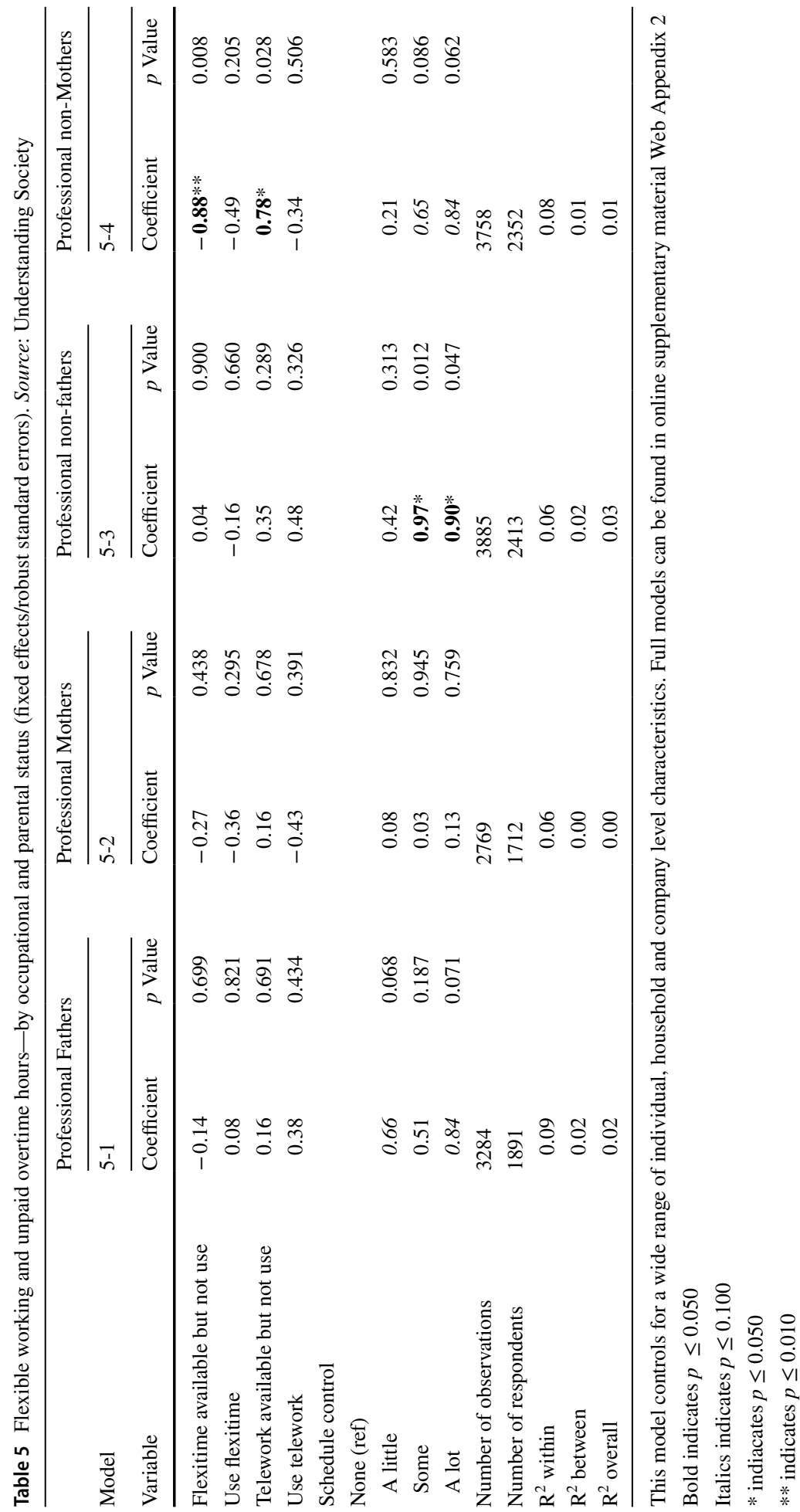




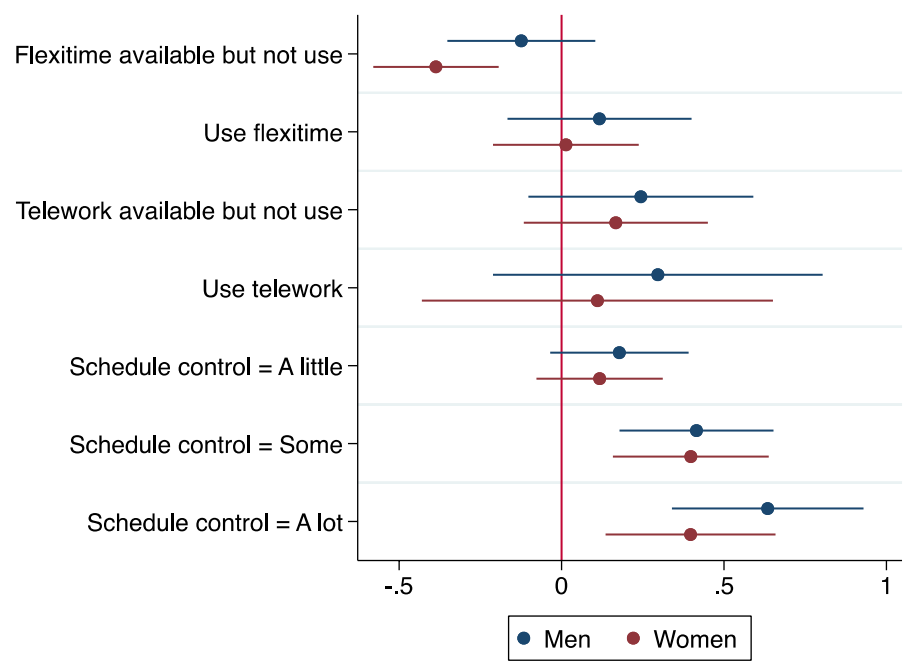

Fig. 1 Increase in unpaid overtime hours due to flexible working for men and women (fixed effects based on full model in Table 1)

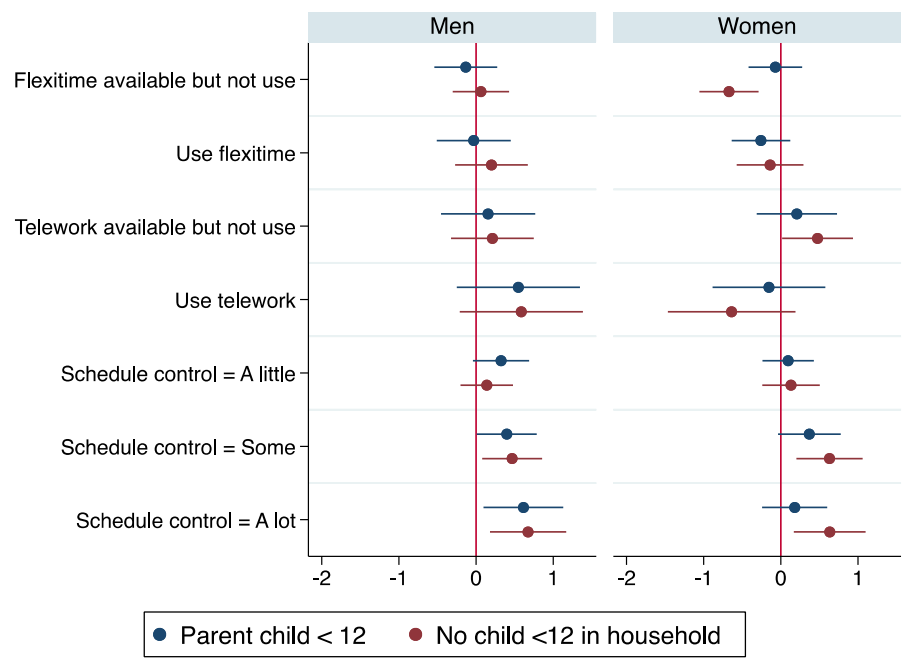

Fig. 2 Increase in unpaid overtime hours due to flexible working for parents versus non-parents (fixed effects based on full model in Table 2)

groups analysed, the access to (but not using) flexitime and teleworking was also not associated with an increase in overtime hours. There were few exceptions. For example, for women, gaining access to flexitime but not using it, seemed to slightly reduce their unpaid overtime hours (Fig. 1, Table 1 Model 1-2). This pattern remains stable for the other sub-group analyses, with the exception of mothers where the relationship was insignificant (Tables 2, 3, 4, and 5). Another thing to note is that for women without children, having telework available while not using it is associated with an increase 


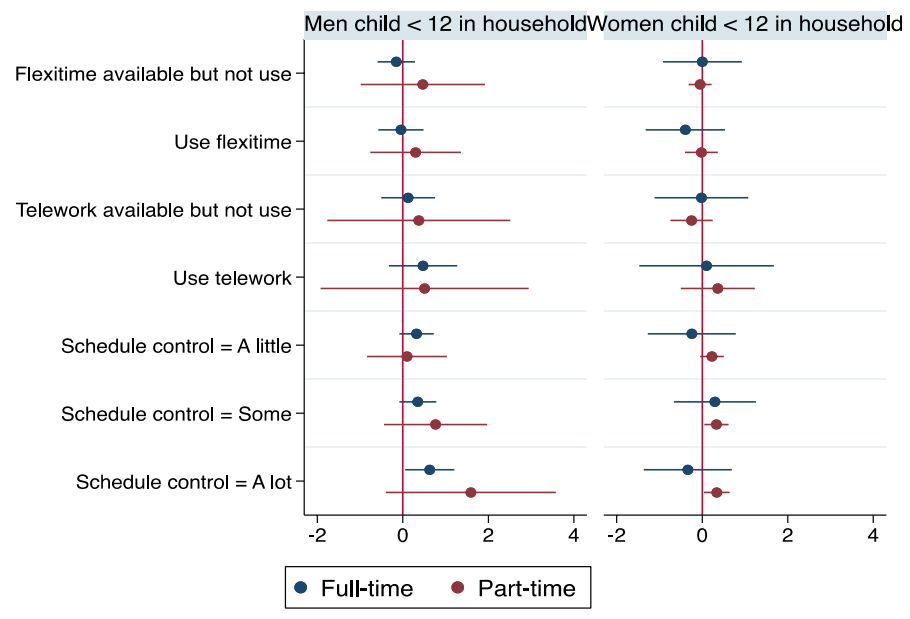

Fig. 3 Increase in unpaid overtime hours due to flexible working for full-time versus part-time working parents (fixed effects based on full model in Table 3)

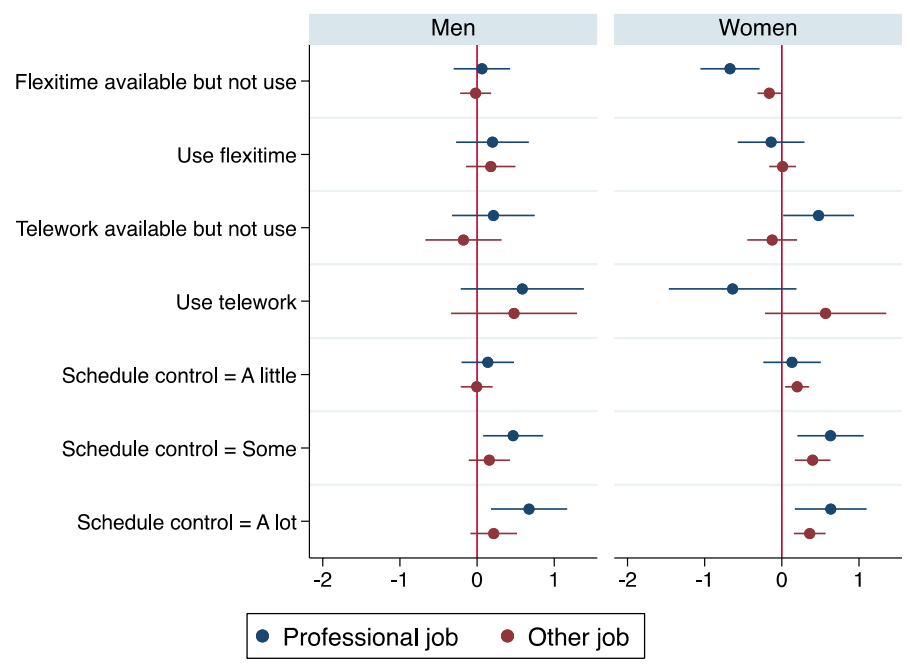

Fig. 4 Increase in unpaid overtime hours due to flexible working for professional versus non-professional jobs (fixed effects based on full model in Table 4)

in unpaid overtime (see Table 2, Model 2-4 and Table 5, Model 5-4). These findings generally support our idea that flexible working primarily introduced as family-friendly arrangements is not associated with the increase in unpaid overtime.

Next, we examine the outcomes for schedule control, which we expect to be more likely used as part of a high-performance work strategy. Unlike the more family-friendly flexible working arrangements, schedule control is associated with working longer unpaid overtime hours supporting Hypothesis 1. Table 1 shows that when men and women get some/a lot of autonomy, they end up working longer unpaid overtime. There is a small difference 


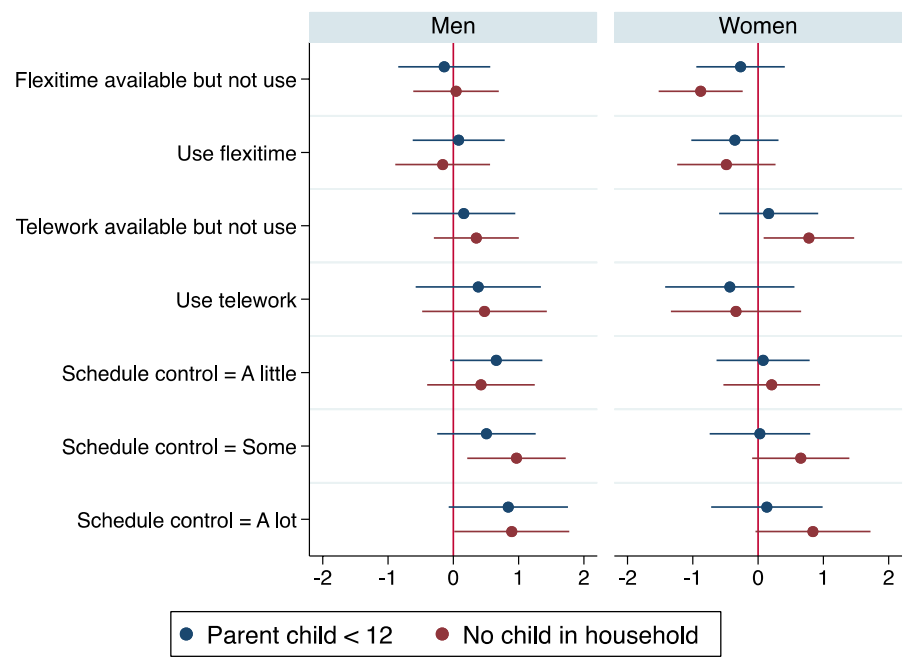

Fig. 5 Increase in unpaid overtime hours due to flexible working for professional parents versus non-parents (fixed effects based on full model in Table 5)

between men and women, e.g. 40 versus 25 more minutes for men compared to women respectively when they get a lot of schedule control. However, both groups show a statistically significant increase in unpaid overtime hours and Fig. 1 suggests that this difference between men and women is not statistically significant. In sum, we found little support for Hypothesis $2 \mathrm{a}$ which stated that performance oriented flexible working would be associated with an increase in unpaid overtime hours for men only.

Hypothesis $2 b$ and $2 c$ expected that the gender differences were more prevalent for those with parental responsibilities. Thus, we compare parents and non-parents in their increase of unpaid overtime when using flexible working arrangements in Table 2 and Fig. 2. Women without young children in the household increased their unpaid overtime hours when gaining schedule control, and to a similar extent as men without children (Model 2-3 and 2-4). However, as expected, for mothers with young children schedule control did not seem to significantly increase their unpaid overtime hours (Model 2-2). On the other hand, parental status did not seem to change the amount of unpaid overtime hours done by men gaining schedule control. In sum, the results support hypothesis $2 \mathrm{~b}$ that the division, rather than being between men and women, is more between mothers, and others groups of workers-i.e., men and women without children.

Hypothesis $2 \mathrm{c}$ expected that for full-time working parents, there would be a significant increase in unpaid overtime hours through schedule control, but that this relationship would not exist for part-time working mothers. Table 3 and Fig. 3 compares full-time working parents and their increase in unpaid overtime due to flexible working to that of part-time working parents. First, it is important to note that majority of the fathers in our sample worked full-time (3407 out of 3704), while relatively few mothers in our sample worked full-time (1300 out of 3688). Thus, the results for full-time working fathers is not dissimilar to that of all fathers. Unlike our expectations, full-time working mothers did not significantly increase their unpaid overtime hours when having schedule control-even showing negative albeit non-significant coefficient signs. Interestingly, we see a slight increase in unpaid overtime hours associated with schedule control for part-time working 
mothers. It may be that part-time working mothers have a greater capacity to extend their (unpaid) overtime hours than full-time working mothers who may have maxed out on their capacity to work any longer. On the other hand, this could be a result of the negative stigma part-time working carries, especially for mothers (Chung 2018b). Part-time working mothers may have to demonstrate their devotion towards work and work longer when they have more control over their work schedules because of the negative assumptions others hold in regards to part-time working mothers' work commitment and productivity.

Next, we distinguish the effect of flexible working for higher and lower occupational groups. As shown in Table 4 and Fig. 4, for men, the increase in unpaid overtime hours due to schedule control is predominately driven by workers in higher occupational groups-i.e., managers and/or (associate) professionals. Schedule control does not lead to a significant increase in unpaid overtime for men in medium/lower occupational groups. For women, however, although on average managerial and professional women seem to increase their unpaid overtime hours slightly more than other women, the difference is not large and the latter also significantly increase their unpaid overtime hours when getting schedule control. This only partially confirms hypothesis $2 \mathrm{~d}$, where it was expected that only higher occupational groups increased their unpaid overtime hoursthis appears to be true for men, but not for women.

We also expected, hypothesis $2 \mathrm{e}$, that mothers in professional roles would have limited capacity to increase their unpaid overtime hours due to the competing demands coming from the family sphere. We expected that the positive relationship between schedule control and unpaid overtime hours for professional women would be mainly due to childless women, while the relationship would exist amongst both childless men and fathers. Table 5 provides only weak evidence of this claim. Albeit only significant at the $p<0.100$ level, fathers also increase their unpaid overtime hours when getting schedule control, though there appears to be more evidence for this relationship among childless men. Again, for mothers, even those in professional and managerial roles, schedule control does not significantly increase their unpaid overtime hours. On the other hand, women without children under the age of 12 in the household who are working in professional and/or managerial roles increased their unpaid overtime hours when getting access to schedule control to a similar extent as men, but like professional fathers only significant at the $p<0.100$ level.

\subsection{Robustness Checks (see Online Appendix)}

We performed a series of robustness checks to see how sensitive our results were to various specifications of our model (see online supplementary material Web Appendix 3). We assessed whether it matters that we included other types than pure time flexibility to assess flexitime, balanced the data to having participated in all three waves, no top-coding for unpaid overtime, and imputing missing data. These robustness checks indicate that our conclusions are robust for the precise definition of flexitime, having unbalanced data, topcoding the dependent variable, and missing data. We also looked at total working hours rather than unpaid overtime. This did change the results, but this is not surprising as we are investigating a different phenomenon. In fact, we believe this underlines the importance of investigating unpaid overtime separately as unpaid work may go unnoticed when we look at total (employment) working hours.

Finally, we investigated the use of a continuous dependent variable when this is not normally distributed (many employees did not work any overtime). For this, we investigated 
Tobit panel models, but these could only be compared to the random effects models (which can be found in online supplementary material Web Appendix 2). Results show that of the variables of interest in all our models only two variables became insignificant when using a Tobit model (namely availability and use of flexitime on unpaid overtime of childless men). For the remainder some variables that were insignificant in the original random effects models became significant (using $p=0.050$ as threshold), which suggests we may underestimate some effects. However, most conclusions remained the same suggesting that treating unpaid overtime as a continuous dependent variable may not be problematic (though preferably we would have been able to check this for the fixed effects models included in this paper as well). See online supplementary material Web Appendix 3 for more detail on all these robustness checks.

\section{Conclusion and Discussion}

This paper examines whether flexible working can lead to an increase in unpaid overtime hours, examining the case of UK. One main contribution of this paper is that we distinguish between different types of flexible working arrangements; namely those assumed to be introduced mainly for family-friendly purposes (flexitime and teleworking) versus those assumed to be introduced mainly as part of high performance work systems (schedule control). We further investigate whether the association between flexible working and unpaid overtime hours is found for a specific group of workers while not for others, placing special attention on gender, parental status, and occupational class differences.

The results of the study show that when workers gain control over their working schedules, they are likely to increase their unpaid overtime hours. This effect was not found for what we consider the use of more family-friendly oriented flexible arrangements, namely, flexitime and telework, but only for schedule control, which we consider part of a high-performance strategy. This result mirrors that of previous studies which shows that schedule control leads to longer overtime hours (Lott and Chung 2016) and increased work-to-home spill-over (Lott 2018). However, unlike what was found in other existing studies (Kelliher and Anderson 2010; Glass and Noonan 2016) teleworking did not lead to additional unpaid overtime hours, which may be due to the differences in the sample, the definition of overtime, or the differences in the type of teleworking used in these studies compared to ours-ours only includes that where it was done when workers personally needed to use teleworking while such distinctions was not made in other studies.

The results of the study shed light on the importance for future research to distinguish between different types of flexible working arrangements when talking about its impact and not conflate the results between the two rather distinct types of flexible work. More specifically, in relation to our own research question, it leads us to believe that the autonomy paradox as shown in previous studies (e.g., Mazmanian et al. 2013) may need to be clarified. The paradox of expansion of work, especially unpaid hours, when given more freedom over your work is primarily, and perhaps only, found for the type of work control that can be considered to be intended to meet performance enhancing goals. This type of control over one's work could have also been given to workers alongside other control and responsibility, and possibly increased workload as well. In addition, it has been shown that these types of control are provided alongside an incentivised system that increase competition, such as performance related pay (Pongratz and Voß 2003; Chung 2014 and Online Supplementary Material Appendix Table A1-8). This can explain why it leads to increased unpaid overtime hours. 
However, it is also important to note that we found little evidence of workers who started to use the more family-friendly flexible working arrangements becoming less likely to work unpaid overtime. Although flexitime and teleworking did not lead to increased unpaid overtime hours, it also did not seem to drastically reduce it. In other words, there is very little evidence to justify the stigma surrounding flexible working in that those who work flexibly may not contribute to the company as much as other workers (see also, TUC 2017; Working Families 2017; Chung 2018b). Furthermore, although we did not find any evidence for work expansion via longer unpaid overtime hours, it does not leave out the possibility that workers who use the more family-friendly flexible working arrangements may have increased their qualitative work intensity (Green 2001)-i.e., working harder, and being more productive within the same working hours. Based on previous studies (de Menezes and Kelliher 2011; Kelliher and Anderson 2010; Moen et al. 2017) despite not having increased their unpaid overtime hours, they may work harder, may be more committed, loyal and less likely to leave their workplaces, which would eventually provide benefits for the company.

This study also provides a more in depth look into for whom the schedule control paradox can be found, and the discrepancies between groups of workers in the increase in working hours due to schedule control. We found that there are differences across groups of workers depending on gender, parental status, and occupational class. In sum, men, especially men in professional or managerial positions, appear to be the ones where schedule control was most likely to lead to an increase in unpaid overtime hours. However, it should also be noted that women without children increased their unpaid overtime hours significantly and similar to that of men when gaining schedule control. The schedule control paradox was not found for mothers, not even for full time working mothers or mothers in managerial/professional positions. These gender discrepancies in the increase in unpaid overtime through flexible working mirror what was found in previous studies (Lott and Chung 2016; see also, Lott 2018). Yet in the previous study, the gender discrepancy was largely driven by the part-time working women in the sample and full-time working women were not significantly different from men. In our analyses, full-time working mothers did not increase their unpaid overtime hours when gaining schedule control, while parttime working mothers showed a slight increase. We expect this to be largely driven by the fact that for full-time working mothers, there may not be any more room/time for an increase in overtime, due to the competing demands they face from home. This may not be the case for part-time working mothers, where there may be more room for manoeuvre. For full-time working mothers, flexible working could have allowed them to work longer than they would have otherwise (see, Chung and Van der Horst 2018; Fuller and Hirsh 2018). With the autonomy given they may end up working harder during the time they work, but they might be limited in their capacity to further expand their working hours, especially if these hours are unpaid. On the other hand, part-time working mothers may need to work longer to compensate for the possible stigma attached to them especially when their schedules deviate away from the normal working hours to ensure that they do not suffer from further negative career consequences (Chung 2018b). More research is needed to be able to tease out exactly why this autonomy paradox happens in different ways for different groups in the population.

There was a slight reduction in unpaid overtime hours for women when flexitime was made available but they did not used it. More investigation is needed as to why this is the case. It may be that although we have controlled for a wide range of factors regarding the worker, their family/household, and their workplaces, the availability of flexitime may be capturing a characteristic of workers or change in employment that is time-varying 
and unobserved. Future study should also look into other confounding factors that may change the results of this study; for example, schedule control may merely be an indicator of some other changes in the job that were not observed, and rather than the control itself, workers' increase in unpaid overtime may be due to these other changes. Furthermore, research should establish the causality of these relationships. It may be that those who increase their unpaid overtime gain access to schedule control to better manage their work, rather than the other way around. Despite the fact that employer's and workers' motivation for using/providing flexible working arrangements were a key factor in distinguishing the influence of flexible working on unpaid overtime hours, we were unable to examine these motivations directly. Future studies should thus try to examine these issues further and try to incorporate the motivations behind the provision and take up of flexible working arrangements when examining the varying outcomes it may result in. Finally, the categories of workers used to investigate the variation in the relationship between flexible work and unpaid overtime may be further refined in the future.

Notwithstanding these limitations, this study has provided a useful understanding of the outcomes of flexible working and the possible influence it can have on workers adding to the existing literature. One implication to note from this study is how increases in schedule control may exacerbate the existing problems of unpaid overtime work and long hours culture existing in the UK. In 2017 alone, UK workers put in a total of two billion unpaid overtime hours, contributing to the vast amount of workers working long hours (of $48 \mathrm{~h}$ or more a week) (Sellers 2018). Policy makers should ensure that flexible working and providing workers with more control over their work is not misused to increase workloads without compensation and without breaking existing labour laws, such as the European working time directive. Another main policy implication of this study is that the rise of flexible working, especially high-performance strategy driven arrangements, can indirectly lead to an increase in the gender wage gap. Overtime hours is one of the strongest determinants of promotion chances and pay in the longer term for workers (Francesconi 2001; Pannenberg 2005). Given the unequal capacity between men and women to adhere to this "ideal worker culture", such culture of rewarding long hours of (unpaid additional) work is one of the most important cause of the persistent gender wage gap (Cha 2013; Goldin 2014). Although the family-friendly flexible working arrangements may help women stay in or get back into the labour market, the more performance-oriented flexibility may act as another mechanism to further increase the gap between genders, especially during parenthood. Based on this, a way forward towards greater gender equality in the labour market may be for policy makers to find ways to encourage men to take up the more family-friendly flexibility arrangements, or ensure that neccessary steps are taken to reduce the barriers that hinder such use. Such equal take up of family-friendly flexible working arrangements will help encourage a more equal division of household work and care between men and women. Furthermore, to the degree unpaid overtime indeed leads to more promotion opportunities and higher salaries, policy makers should provide protective mechanisms for workers, so that those with less capability to work more than their contractual hours are not disadvantaged in their career chances. Flexible working can provide workers with better work-life balance and enhanced gender equality (for more see, Chung and Van der Lippe 2018). It is important to provide the right type of flexible working, within the right form of organisational and national contexts (Van der Lippe and Lippényi 2018; Kurowska 2018) to ensure such positive outcomes.

Acknowledgements The authors would like to thank Tanja van der Lippe, Yvonne Lott, and the anonymous reviewer for their incredibly helpful comments and suggestions on this paper. 
Funding UK Economic and Social Research Council Future Research Leader funding-Work Autonomy, Flexibility and Work-life Balance (ES/K009699/1).

Open Access This article is distributed under the terms of the Creative Commons Attribution 4.0 International License (http://creativecommons.org/licenses/by/4.0/), which permits unrestricted use, distribution, and reproduction in any medium, provided you give appropriate credit to the original author(s) and the source, provide a link to the Creative Commons license, and indicate if changes were made.

\section{References}

ACAS. (2016). The right to request flexible working. http://www.acas.org.uk/index.aspx?articleid=1616. Accessed 29 February 2016.

Allen, T. D., Johnson, R. C., Kiburz, K. M., \& Shockley, K. M. (2013). Work-family conflict and flexible work arrangements: Deconstructing flexibility. Personnel Psychology, 66(2), 345-376.

Appelbaum, E. (2000). Manufacturing advantage: Why high-performance work systems pay off. Ithaca, NY: Cornell University Press.

Bathini, D. R., \& Kandathil, G. M. (2017). An orchestrated negotiated exchange: Trading home-based telework for intensified work. Journal of Business Ethics. https://doi.org/10.1007/s10551-017-3449-y.

Bianchi, S. M., Sayer, L. C., Milkie, M. A., \& Robinson, J. P. (2012). Housework: Who did, does or will do it, and how much does it matter? Social Forces, 91(1), 55-63.

Blair-Loy, M. (2009). Competing devotions: Career and family among women executives. Cambridge, MA: Harvard University Press.

Brescoll, V. L., Glass, J., \& Sedlovskaya, A. (2013). Ask and Ye shall receive? The dynamics of employerprovided flexible work options and the need for public policy. Journal of Social Issues, 69(2), 367-388.

Cech, E. A., \& Blair-Loy, M. (2014). Consequences of flexibility stigma among academic scientists and engineers. Work and Occupations, 41(1), 86-110.

Cha, Y. (2013). Overwork and the persistence of gender segregation in occupations. Gender \& Society, 27(2), 158-184.

Cha, Y., \& Weeden, K. A. (2014). Overwork and the slow convergence in the gender gap in wages. American Sociological Review, 79(3), 457-484.

Chung, H. (2014). Explaining the provision of flexitime in companies across Europe (in the pre- and postcrisis Europe): role of national contexts. WAF working paper 1. Canterbury: University of Kent.

Chung, H. (2017a). National-level family policies and the access to schedule control in a European comparative perspective: Crowding out or in, and for whom? Journal of Comparative Policy Analysis. https:// doi.org/10.1080/13876988.2017.1353745.

Chung, H. (2017b). Work autonomy, flexibility and work-life balance final report. Canterbury: University of Kent. http://wafproject.org/research-outputs/final-report/. Accessed 14 April, 2018

Chung, H. (2018a). Dualization and the access to occupational family-friendly working-time arrangements across Europe. Social Policy and Administration, 52(2), 491-507. https://doi.org/10.1111/spol.12379.

Chung, H. (2018b). Gender, flexibility stigma, and the perceived negative consequences of flexible working in the UK. Social Indicators Research. https://doi.org/10.1007/s11205-018-2036-7.

Chung, H., \& Tijdens, K. (2013). Working time flexibility components and working time regimes in Europe: Using company level data across 21 countries. International Journal of Human Resource Management, 24(7), 1418-1434.

Chung, H., \& Van der Horst, M. (2018). Women's employment patterns after childbirth and the perceived access to and use of flexitime and teleworking. Human Relations, 71(1), 47-72. https://doi. org/10.1177/0018726717713828.

Chung, H., \& Van der Lippe, T. (2018). Flexible working work life balance and gender equality: Introduction. Social Indicators Research. https://doi.org/10.1007/s11205-018-2025-x.

Clark, S. C. (2000). Work/family border theory: A new theory of work/family balance. Human Relations, 53(6), 747-770.

Clawson, D., \& Gerstel, N. (2014). Unequal time: Gender, class, and family in employment schedules. New York: Russell Sage Foundation.

Craig, L., \& Powell, A. (2012). Dual-earner parents' work-family time: the effects of atypical work patterns and non-parental childcare. Journal of Population Research, 29(3), 229-247.

Davis, A. E., \& Kalleberg, A. L. (2006). Family-friendly organizations? Work and family programs in the 1990s. Work and Occupations, 33(2), 191-223. 
de Menezes, L. M., \& Kelliher, C. (2011). Flexible working and performance: A systematic review of the evidence for a business case. International Journal of Management Reviews, 13(4), 452-474.

Dex, S., \& Scheibl, F. (2001). Flexible and family friendly working arrangements in UK based SMEs: Business cases. British Journal of Industrial Relations, 39(3), 411-431.

Durbin, S., \& Tomlinson, J. (2010). Female part-time managers: networks and career mobility. Work, Employment \& Society, 24(4), 621-640.

Eurofound. (2015). Third European Company Survey-Overview report: Workplace practices-Patterns, performance and well-being. Luxembourg: Publications Office of the European Union.

Eurofound and the International Labour Office. (2017). Working anytime, anywhere: The effects on the world of work: Publications Office of the European Union, Luxembourg, and the International Labour Office, Geneva.

Eurostat (2016a). Employment rate by sex, age groups, educational attainment level and household composition. http://appsso.eurostat.ec.europa.eu/nui/show.do?dataset=lfst_hheredty.

Eurostat (2016b). Percentage of part-time employment by sex, age groups and household composition. http://appsso.eurostat.ec.europa.eu/nui/show.do?dataset=lfst_hhptety.

Felstead, A., \& Jewson, N. (2000). In work, at home: Towards an understanding of homeworking. NewYork, London: Routledge.

Francesconi, M. (2001). Determinants and consequences of promotions in Britain. Oxford Bulletin of Economics and Statistics, 63(3), 279-310.

Fuller, S., \& Hirsh, C. E. (2018). "Family-Friendly" jobs and motherhood pay penalties: The impact of flexible work arrangements across the educational spectrum. Work and Occupations. https://doi. org/10.1177/0730888418771116

Gerstel, N., \& Clawson, D. (2014). Class advantage and the gender divide: Flexibility on the Job and at Home. American Journal of Sociology, 120(2), 395-431.

Glass, J. L., \& Noonan, M. C. (2016). Telecommuting and earnings trajectories among American Women and Men 1989-2008. Social Forces, 95(1), 217-250.

Golden, L., Chung, H., \& Sweet, S. (2018). Positive and negative application of flexible working time arrangements: Comparing the United States and the EU Countries. In E. Farndale, C. Brewster, \& W. Mayrhofer (Eds.), The handbook of comparative human resource management (pp. 237-256). Northhampton, MA: Edward Elgar.

Golden, T. D., Veiga, J. F., \& Simsek, Z. (2006). Telecommuting's differential impact on work-family conflict: Is there no place like home? Journal of Applied Psychology, 91(6), 1340-1350.

Goldin, C. (2014). A grand gender convergence: Its last chapter. The American Economic Review, 104(4), 1091-1119.

Green, F. (2001). It's been a hard day's night: The concentration and intensification of work in late twentieth-century Britain. British Journal of Industrial Relations, 39(1), 53-80.

Kelliher, C., \& Anderson, D. (2010). Doing more with less? Flexible working practices and the intensification of work. Human Relations, 63(1), 83-106.

Kelly, E. L., Moen, P., \& Tranby, E. (2011). Changing workplaces to reduce work-family conflict schedule control in a white-collar organization. American Sociological Review, 76(2), 265-290.

Kim, J. (2018). Workplace flexibility and parent-child interactions among working parents in the U.S. Social Indicators Research. https://doi.org/10.1007/s11205-018-2032-y.

Knies, G. (ed.) (2015). Understanding society: The UK household longitudinal study, waves 1-5, user manual. University of Essex, UK: Institute for Social and Economic Research.

Kurowska, A. (2018). Gendered effects of home-based work on parents' capability to balance work with nonwork. Two countries with different models of division of labour compared. Social Indicators Research. https://doi.org/10.1007/s11205-018-2034-9.

Leslie, L. M., Manchester, C. F., Park, T.-Y., \& Mehng, S. A. (2012). Flexible work practices: A source of career premiums or penalties? Academy of Management Journal, 55(6), 1407-1428.

Lewis, J., Knijn, T., Martin, C., \& Ostner, I. (2008). Patterns of development in work/family reconciliation policies for parents in France, Germany, the Netherlands, and the UK in the 2000s. Social Politics: International Studies in Gender, State \& Society, 15(3), 261-286.

Lott, Y. (2018). Does flexibility help employees switch off from work? Flexible working-time arrangements and cognitive work-to-home spillover for women and men in Germany. Social Indicators Research. https://doi.org/10.1007/s11205-018-2031-z.

Lott, Y., \& Chung, H. (2016). Gender discrepancies in the outcomes of schedule control on overtime hours and income in Germany. European Sociological Review, 32(6), 752-765.

Lyonette, C. (2015). Part-time work, work-life balance and gender equality. Journal of Social Welfare and Family Law, 37(3), 321-333. 
Maume, D. J. (2006). Gender differences in restricting work efforts because of family responsibilities. Journal of Marriage and Family, 68(4), 859-869.

Mazmanian, M., Orlikowski, W. J., \& Yates, J. (2013). The autonomy paradox: The implications of mobile email devices for knowledge professionals. Organization Science, 24(5), 1337-1357.

Moen, P., Kelly, E. L., Lee, S.-R., Oakes, J. M., Fan, W., Bray, J., et al. (2017). Can a flexibility/support initiative reduce turnover intentions and exits? Results from the Work, Family, and Health Network. Social Problems, 64(1), 53-85.

Moen, P., \& Yu, Y. (2000). Effective work/life strategies: Working couples, work conditions, gender, and life quality. Social Problems, 47(3), 291-326.

Munsch, C. L. (2016). Flexible work, flexible penalties: The effect of gender, childcare, and type of request on the flexibility bias. Social Forces, 94(4), 1567-1591.

Noonan, M. C., Estes, S. B., \& Glass, J. L. (2007). Do workplace flexibility policies influence time spent in domestic labor? Journal of Family Issues, 28(2), 263-288.

Ortega, J. (2009). Why do employers give discretion? Family versus performance concerns. Industrial Relations: A Journal of Economy and Society, 48(1), 1-26.

Osterman, P. (1995). Work/family programs and the employment relationship. Administrative Science Quarterly, 40(4), 681-700.

Pannenberg, M. (2005). Long-term effects of unpaid overtime: Evidence for West Germany. Scottish Journal of Political Economy, 52(2), 177-193.

Park, A., Bryson, C., Clery, E., Curtice, J., \& Phillips, M. (2013). British Social Attitudes: The 30th Report. London: NatCen Social Research.

Pongratz, H. J., \& Voß, G. G. (2003). From employee to 'entreployee': Towards a 'self-entrepreneurial'work force? Concepts and Transformation, 8(3), 239-254.

Putnam, L. L., Myers, K. K., \& Gailliard, B. M. (2014). Examining the tensions in workplace flexibility and exploring options for new directions. Human Relations, 67(4), 413-440.

Rapoport, R., Bailyn, L., Fletcher, J. K., \& Pruitt, B. H. (2002). Beyond work-family balance: Advancing gender equity and work performance. San Francisco: John Wiley \& Sons.

Riedmann, A., Bielenski, H., Szczurowska, T., \& Wagner, A. (2006). Working time and work-life balance in European companies: Establishment survey on working time 2004-2005. Luxembourg: European Foundation for the Improvement of Living and Working Conditions.

Schieman, S., Milkie, M. A., \& Galvin, P. (2009). When work interferes with life: Work-nonwork interference and the influence of work-related demands and resources. American Sociological Review, 74(December), 966-988.

Sellers, P. (2018). Work your proper hours day-tackling the culture of unpaid overtime. London: Trades Union Congress.

Singley, S. G., \& Hynes, K. (2005). Transitions to parenthood work-family policies, gender, and the couple context. Gender \& Society, 19(3), 376-397.

Steiber, N. (2009). Reported levels of time-based and strain-based conflict between work and family roles in Europe: A multi-level approach. Social Indicator Research, 93(3), 469-488.

Swanberg, J. E., Pitt-Catsouphes, M., \& Drescher-Burke, K. (2005). A question of justice disparities in employees' access to flexible schedule arrangements. Journal of Family Issues, 26(6), 866-895.

Tomlinson, J. (2007). Employment regulation, welfare and gender regimes: A comparative analysis of women's working-time patterns and work-life balance in the UK and the US. The International Journal of Human Resource Management, 18(3), 401-415.

TUC. (2017). Better jobs for mums and dads. London: Trades Union Congress.

Van der Lippe, T., \& Lippényi, Z. (2018). Beyond formal access: Organizational context, working from home, and work-family conflict of men and women in European workplaces. Social Indicators. https:// doi.org/10.1007/s11205-018-1993-1.

Voydanoff, P. (2004). The effects of work demands and resources on work-to-family conflict and facilitation. Journal of Marriage and, Family, 398-412.

Warren, T. (2015). Work-time underemployment and financial hardship: Class inequalities and recession in the UK. Work, Employment \& Society, 29(2), 191-212.

West, C., \& Zimmerman, D. H. (1987). Doing gender. Gender \& Society, 1(2), 125-151.

Williams, J. (1999). Unbending gender: Why family and work conflict and what to do about it. New York: Oxford University Press.

Williams, J., Blair-Loy, M., \& Berdahl, J. L. (2013). Cultural schemas, social class, and the flexibility stigma. Journal of Social Issues, 69(2), 209-234.

Wiß, T. (2017). Paths towards family-friendly working time arrangements: Comparing workplaces in different countries and industries. Social Policy \& Administration, 51(7), 1406-1430. https://doi. org/10.1111/spol.12270. 
Wood, S. J., \& De Menezes, L. M. (2010). Family-friendly management, organizational performance and social legitimacy. The International Journal of Human Resource Management, 21(10), 1575-1597.

Working Families. (2017). Modern family index 2017. London: Working Families.

Yasbek, P. (2004). The business case for firm-level work-life balance policies: a review of the literature. http://www.futureofwork.govt.nz/PDFs/FirmLevelWLB.pdf.

Young, Z. (2018). Women's Work: How mothers manage flexible working in careersand family life. Bristol: Bristol University Press. 